\title{
Effect of Talk on English as a Foreign Language Writing Development and Language Learner Identity: A Study of Chinese College Students
}

\author{
Xuexing Li, Hongquan Yang*, Han Yan \\ Department of Foreign Languages and Preschool Education, Beijing Institute of Economics and Management, Beijing, China \\ Email address: \\ xuexingli@biem.edu.cn (Xuexing Li), hongquanyang@biem.edu.cn (Hongquan Yang), yanhan@biem.edu.cn (Han Yan) \\ ${ }^{*}$ Corresponding author
}

To cite this article:

Xuexing Li, Hongquan Yang, Han Yan. Effect of Talk on English as a Foreign Language Writing Development and Language Learner Identity: A Study of Chinese College Students. International Journal of Language and Linguistics. Vol. 9, No. 5, 2021, pp. 258-268. doi: $10.11648 /$ j.ij11.20210905.13

Received: September 14, 2021; Accepted: September 30, 2021; Published: October 12, 2021

\begin{abstract}
Writing is regarded as a huge challenge for students who study English as a foreign language (EFL). Confronted with the poor writing performance of Chinese students, researchers have been exploring the effective approaches to teaching EFL writing. "Talk for writing" is a widely studied field in countries such as the UK and New Zealand. However, reliable literature in this domain is scarce in China, and most of of it is short-term or unstructured research. Thus, this article aims to explore how (EFL) writing development and language learner identity are affected by talk, a process derived from social constructivism, entailing expounding, exchange, negotiation, reflection, and development. The 18-week longitudinal study applied a "talk for writing" approach to college English writing classes with 74 English-major students from a higher vocational college. This research, employing both quantitative methods and qualitative methods, yielded rich and dynamic results. (1) The quantitative data indicated that the "talk for writing" approach improved students' academic writing attainment on the whole. Particularly, the cohort of so-called "modest writers" benefited the most from it. Moreover, this approach, to a large extent, exerted a positive impact on the reconstruction of students' language learner identity. (2) The qualitative data identified the types of talk that supported writing and provided evidence for the ways in which talk supported students' ability to generate ideas, to use talk as oral rehearsal in preparation for writing, and to improve their linguistic accuracy. It also gave insights into students' views on this approach. Also, this approach developed students' engagement, motivation and confidence in English writing and delineated the negotiating trajectories of students' language learner identity.
\end{abstract}

Keywords: EFL Writing, Talk for Writing, Language Learner Identity, Chinese College Students, Strategic Talk, Evaluative Talk, Constructive Talk

\section{Introduction}

Writing is regarded as a huge challenge for students who study English as a foreign language (EFL). According to Hu's study, the teaching of EFL writing in mainland China mainly adopts the linguistic approach which places emphasis on the reproduction of language-forms and the accuracy of grammar $[1,2]$. The EFL writing instruction is carried out as a spectrum of repetitive exercises including "filling in the blanks, following pattern drills, and producing error-free text" (p. 25) [3]. Drawing on the report from the British Council of Culture and Education this pattern of a "low writing score" in IELTS, is found across mainland China [4].

In light of this situation, scholars and researchers tried their best to explore and improve the EFL writing pedagogy in China. For example, according to You, "pedagogies, such as pre-writing and multiple-drafting activities, are identified in classrooms and textbook publishing" (p. 97) [5]; Yunus et al. pointed out that the advanced communication technology has provided opportunities for online collaborative learning among students who can write blogs and exchange ideas with other fellows [6]; based on the alignment theory, Wang and Wang put forward a "writing continuation after reading" model to improve students' writing proficiency through 
accumulating necessary vocabulary, syntax and structure from the reading section [7, 8]. In the research of English writing in higher vocational colleges, according to Huang and Fan, the current popular teaching methods include product approach, process approach, genre approach, content-based teaching, project-based teaching, task-based teaching, etc [9]. And the "reading for writing", "writing continuation after reading" methods have also been tried out in classes in resent years [10-12].

"Talk for writing" is a widely studied field in countries such as the UK and New Zealand, but most of the research has been conducted among primary and secondary school students, little literature can be traced back to college students [13-15].

As to the research field of "talk for writing" in China, reliable literature is scarce, and most of it is short-term or unstructured research. Most studies were conducted among primary and secondary school students [16-20], there are few empirical studies on "talk for writing" in college English writing [21].

Hence, to carry out a longitudinal study on how talk affects college students' writing development and their language learner identity can not only add reliable literature to "talk for writing" but also provide reference for EFL writing teaching.

\section{Literature Review}

Related theoretical and empirical studies on "talk for learning", "talk for writing", and "talk mediates language learner identity negotiation" will be drawn on to construct and justify the research as talk is the focus in supporting learning, in the development of writing and in the construction and negotiation of language learner identity.

\subsection{Talk for Learning}

"Talk for learning" probes the ongoing debate about what "talk" entails and how this informs the ways talk for learning is approached in classroom. Vygotsky's view on language and thinking is highlighted which regards talk as a mediating tool in formulating thinking and learning [22]. Also, the theory of social constructivism lays a foundation for classroom interaction and learning.

Britton had proposed that classroom talk should be seen as the foundation for all learning; it is much more than just the classroom "teacher talk" of instruction [23]. Barnes, Britton and Rosen analyzed in their book, the significance of small-group talk and learning in relation to the opportunity and time students gained to articulate their thoughts, negotiate ideas and develop new ideas and new knowledge. From this stance, language shapes the ways of thinking and assists learning [24].

In relation to educational dialogue, an extensive body of research favors the view that learners' talk in collaborative interactions is central to learning in the context of a classroom because collaborative talk can support learners' development in higher-cognitive processes, conceptual understanding, the ability to articulate individual perspectives and confidence in discursive exchanges [22, 25-28]. Particularly, Sutherland's study indicated that adopting a dialogic stance in teaching and learning enabled marginalized students to recognize their power in collaboratively constructing meaning with other peers and enhanced their confidence in sharing their voices in group talk [28]. This relates to one of the aspects that this research explores, that is, how talk can include the voices of marginalized students, especially, the low-attaining students and support their learning.

Evidence also shows how collaborative talk improves academic performance in a range of subjects such as in mathematics, science and English both in reading and writing [29-32].

\subsection{Talk for Writing}

"Talk for writing" extends the discussions on "talk for learning" to a more specific field which has been studied in various contexts including EFL classes in China.

According to Parr, Jesson and McNaughton's research conducted under the national primary literacy curriculum in New Zealand, three ways of how talk supporting writing have been summarized. First, talk supports writing in generating ideas for writing. In this sense, talk shapes students' thinking and mediates their articulation of ideas and contents prior to independent writing. Second, the dialogic classroom talk scaffolds novice writers' writing. Through dialogue, students evaluate, give feedback to each other, hence, the novice writers have the opportunity to revise their thinking and ideas. Third, readers' talk supports writing, that is, talking about a piece of reading in terms of its structure and linguistic choices can demonstrate the writing process explicitly to students. Therefore, students can apply the explicit writing knowledge learned from readers' talk to their independent writing [14].

According to Fisher et al., the Talk to Text project had investigated how to support students' writing by providing explicit opportunities for talk in classroom from December 2004 to the end of November 2006. This project was carried out among 6 classes from 5 primary schools in two areas of the south west of England. Three elements were identified as the strategic guidance for talk: idea generation, oral rehearsal and metacognition. This research highlights the strategic use of talk to support writing and reveals the key features of talk which highly contribute to the development of students' writing. The talk activities for writing enhanced students' engagement in the preparation for writing and their enthusiasm for writing including the low achievers in class [15].

Based on Beard's work, the "talk for writing" approach which was promoted by National Strategies together with Pie Corbett in 2007 and 2008 is now an essential part of Primary Writing Project in the UK [33].

However, criticism of "talk for writing" can also be noted. For example, Christie put forward that using talk as a preparation for writing poses no challenge for students, cannot develop students' thinking capacity or support their learning of writerly form [34]. 
Research on talk for EFL writing in China is scarce though the efficacy of talk for writing is evidenced by some, for instance, enhancing students' writing performance in terms of the linguistic aspects such as sentence patterns, grammar and vocabulary, improving their writing attainment, and stimulating their interest and motivation [18, 20, 21, 35]. Yang's study also evidenced the improvement in content, ideas and structure [18].

In the research field of "talk for writing" in college, Wang carried out a 5-10 minute "talk and writing" activity in each class for a semester. Through a final exam, she made a quantitative analysis and concluded that the method of "combining talk and writing" has improved higher vocational students' learning and application of vocabulary and grammar, as well as their written expression ability. Although this study takes "the combination of talk and writing" as the research topic, it is not fully implemented in classroom practice. Instead, she only spent 5-10 minutes on lead-in or class summary to conduct the teaching intervention, without a complete teaching process of "the combination of talk and writing". Moreover, this study merely compared the scores of the implemented class and the comparison class after one-semester intervention to make a quantitative analysis, and ignored the writing development trajectory of students during that process, the feelings and understanding of students and teachers on the method of "combining talk and writing", as well as the effects of this method on students' writing confidence, learning interest and learning motivation [21].

In sum, talk supports students' writing in various ways, for example, supporting their idea generation, oral rehearsal, metacognition, scaffolding their preparation for writing in terms of ideas and content, discussing the writing process explicitly $[14,15]$. As for the efficacy of talk for writing approach, it improves students writing performance, writing attainment, interest, motivation and engagement $[15,18,20$, 21, 35-37].

\subsection{Talk Mediates Language Learner Identity Negotiation}

In this section, the notion of "language learner identity" is explored and how talk mediates the negotiation and reconstruction of language learner identity is discussed.

The notion of "language learner identity" is developed on the ample theoretical and empirical research on language learning and identity.

Based on the empirical research on language learning and identity, Norton defines identity as "the way a person understands his or her relationship to the world, how that relationship is structured across time and space, and how the person understands possibilities for the future" (p. 5) (p. 4) [38, 39]. In line with Norton's notion, identity formation is, according to Hawkins, a process during which the individual communicate and interact with the surroundings, and in turn, negotiate their perspectives [40]. This view takes a sociocultural approach and puts ample emphasis on the interaction between the learner and others by recognizing the feature of identity is unfixed, undergoing constant negotiation and re-construction.
According to Ellis and Timmis, foreign language learners hold different views towards "target language", "target language speakers", "target language cultures" and "themselves as members of their own cultures" which, in turn, affect their learning of the target language [41, 42]. These views along with their learning experience constitute their "language learner identity" which is multiple, changing, and sometimes, struggling and contradictory $[43,44]$.

Based on the work of a spectrum of researchers, three essential constructs are identified as "investment", "agency", and "imagined communities (imagined identities)" [38, 45-47].

As is discussed earlier, taking the sociocultural approaches, talk is the mediating tool for learning. Also stemming from the sociocultural theory, language learner identity is constantly negotiated and reconstructed along with the learning experience through the interaction among learners and with other cultural artefact in a given context. Set foreign language learning in the classroom context, small groups of students can be taken as a "community of learners" where learners share ideas, exchange views, reflect their own thinking, negotiate and reconstruct their identities through talk [48, 49].

Classroom talk, in some way, enhances learners' agency, further, increases their "investment" in learning, as talk is both cognitive and social [25]. When they engage in talk, students' cognitive capacities are initiated, exercised, and developed through social interactions with their group members and with cultural artefact, including books, videos, audios, and other forms of information. Also, through talk students take on and negotiate their identities in specific discourse contexts. Therefore, classroom talk mediates students' thinking, their agency, investment, and learner identity.

In sum, classroom talk can provide valuable reference for analyzing individuals' learning trajectories, social interactions, and identity negotiation and re-construction.

\section{Research Questions}

(1) What does talk entail?

(2) In what ways does classroom talk affect college students' academic English writing?

(3) How does talk affect students' language learner identities?

\section{Methodology}

\subsection{Research Design}

This research was designed to be an 18-week longitudinal research and was conducted in a higher vocational college in Beijing, China. The participants of the study were required to take a 90-minute English writing class that adopted the "talk for writing" approach once a week. Each class was designed to include four activities. The first activity was peer review in which students were supposed to engage in small-group talk to review other peers' written texts and gave feedback to them. The second activity was 
the new topic introduction in which the new assignment for writing was introduced and the key points of content were discussed between the teacher and the students. The third activity was the student-student group talk in which students would engage in small-group talk, usually 4 students in a group, to discuss the new assignment and complete a planing sheet and a feedback sheet that were used to guide the group talk. The fourth activity was independent writing. The writing topics were selected from standardized mock IELTS tests. Also, the participants were requested to do a pretest and a post-test, and two questionnaires before and after the teaching intervention.

The research applies mixed methods, that is, using both the quantitative methods and qualitative methods. The quantitative methods include carrying out a pretest and a post-test; and answering questionnaires while the qualitative methods consist of writing class observation notes, recording videos, conducting interviews and collecting writing samples. The quantitative methods and the qualitative methods are complementary in relation to carrying out research in the educational context, especially in classrooms where the surroundings are dynamic instead of static just as Reams and Twale pointed out, a mixed-methods approach is "necessary to uncover information and perspective, increase corroboration of the data, and render less biased and more accurate conclusions" (p. 133) [50].

In order to investigate to which cohort of students talk benefits their writing the most, each of the 74 participants was labeled as "competent writer", "modest writer" or "limited writer" based on the their pretest scores. Students rank top 24 were labeled as "competent writers" while students ranking the last 26 were marked as "limited writers". All the "labeling" was confidential to students and was designed only for this investigation.

\subsection{Subjects}

The 74 participants come from three parallel sophomore classes of English majors with 24, 26 and 24 students in Class A, Class B, Class C respectively.

Four students from Class $\mathrm{C}$ were chosen as the case-study subjects for careful observation including one girl from the "competent writer" group, one girl from the "modest writer" group and one girl and one boy from the "limited writer" group. And they were selected based on an opt-in method.

\subsection{Data Collection and Analyses}

For the quantitative data collection, a pretest and a post-test were conducted to record students' writing performance before and after the "talk for writing" teaching intervention. Students were tested by the writing part of a sample test paper for IELTS (International English Language Testing System) and were marked according to the marking criteria of IELTS writing by two experienced English writing teachers. Also, two questionnaires were answered to record their views on "talk for writing" and their perceptions of themselves as language learners. SPSS was used to analyze the change and development.

As for qualitative data collection, data from classroom observation notes, video recordings, interviews, and students' writing samples were collected to look into the meticulous writing development trajectories and delicate language learner identity negotiation.

\section{Findings and Discussions}

\subsection{Pretest and Post-test}

Table 1. The mean scores of different groups of writers in pretest and post-test.

\begin{tabular}{lll}
\hline Groups & Pretest & Post-test \\
\hline Competent & $85.58(\mathrm{SD}=3.90)$ & $91.08(\mathrm{SD}=3.20)$ \\
Modest & $73.83(\mathrm{SD}=3.06)$ & $84.92(\mathrm{SD}=3.36)$ \\
Limited & $61.12(\mathrm{SD}=3.28)$ & $67.58(\mathrm{SD}=5.20)$ \\
All & $73.18(\mathrm{SD}=10.68)$ & $80.82(\mathrm{SD}=10.89)$ \\
\hline
\end{tabular}

Table 2. Wilcoxon matched-pairs signed rank test of pretest and post-test.

\begin{tabular}{ll}
\hline & Post-test - Pretest \\
\hline$Z$ & $-7.410^{*}$ \\
Asymp. Sig. (2-tailed) & .000 \\
\hline${ }^{*}$ Based on negative ranks. &
\end{tabular}

The tables above present the mean scores of different groups of writers and the Wilcoxon test results. From Table 1, it can be seen clearly that the mean scores of all the 74 participants' writings for the pretest were $73.18(\mathrm{SD}=10.68)$ and $80.82(\mathrm{SD}=10.89)$ for the post-test with a growth of 7.64 marks. In order to investigate whether the gap of the mean scores of the two tests was statistically significant, a Wilcoxon matched-pairs signed rank test was conducted. The results (Table 2) indicated that the mean scores of the two tests differed highly considerably. That means the "talk for writing" approach significantly improved students' writing attainment on the whole.

Further, three paired samples $t$ tests were carried out to explore the statistical significance between the pretest and post-test mean scores of the three different attaining groups. The results yielded a similar statistical pattern, with the $p$ (2-tailed) of .000,.000,.000, respectively for the "competent writers", "modest writers" and "limited writers", which means the differences of the mean scores in the two tests were highly significant. That is, the writing performance of students from the three attaining groups was all greatly improved. It also can be drawn that the gap between the mean scores of the "modest writer" group was the most significant, with a growth of 11.09 marks. That indicates that the "modest writers" made the greatest progress among the three attaining groups.

In sum, the comparison of the pretest and the post-test presents a significant efficacy of the talk for writing approach, and it demonstrates the "modest writers" benefited the most from the approach despite a cross-board progress of all the attaining groups. 


\subsection{The Questionnaires}

74 valid questionnaires were collected before the teaching intervention and 72 after.

The questionnaire survey aims to investigate:

(1) The comparison of students' views on the English writing approach employed in their high school and the "talk for writing" approach;

(2) The changes of students' motivation, confidence and interest in English writing;

(3) The changes of students' perceptions on themselves regarding English writing and learning English.

First, the findings in participants' views on the "talk for writing" approach witnessed a significant increase of the choice proportion in the "helpful" ways. In consistent with the findings in the writing approaches in secondary schools, students chose "vocabulary and proper diction" as the aspect that benefited them the most, with a over $10 \%$ rise to $65.28 \%$, along with "grammatical control" growing slightly to $41.67 \%$. What worth noting is that participants considered the "talk for writing" approach particularly helped them to "generate ideas and enrich the content" with a nearly a quarter growth in choice. Also, the figures for "critical thinking" and "fun" experienced a double and triple increase respectively. On the contrary, the percentage of students who thought it was helpful in "organization, coherence and cohesion" dropped approximately $16 \%$ to $38.89 \%$. The support to writing in accumulating "sentence structures" remained stable at around $48 \%$. Furthermore, the proportion of those surveyed who regarded the approach "unhelpful" was $9.72 \%$, about a half decrease from the figure of the approaches adopted in secondary schools.

Based on these figures, the "talk for writing" approach benefits students' writing development more in the aspects "vocabulary and proper diction" and "sentence structures" than the approaches employed in secondary schools. Particularly, its support in "generating ideas and enriching the content" is salient. Moreover, it delineates a similar supporting pattern as other approaches in helping improve "grammatical control".

Second, regarding students' confidence, interest and motivation in English writing, the results are intriguing. About four in five students perceived themselves as English writers after the "talk for writing" intervention. Participants believed this approach had helped them a lot in boosting their "confidence" (31.94\%, approximately 3 times of that of other approaches) and arousing their "interest and motivation" (50\%, more than 3 times of that of other approaches). The figures for "confidence" and "interest and motivation" are approximately three times and more than three times higher than other approaches respectively.

The results presents students' positive change in attitude to English writing after the "talk for writing" intervention.

Third, students' perceptions on themselves regarding English learning present a significant change. Comparing the figures before and after the "talk for writing" intervention, the proportion of participants regarding themselves as "passive learners" has dropped more than half from 37.84\% to $15.28 \%$. In contrast, the figure for "exam-driven learners" has almost doubled from $18.92 \%$ to $33.33 \%$. And the percentage of "active learners" has witnessed a growth of around a quarter to $30.56 \%$. The ratio of "extremely passive learners" and "passionate learners" remained stable despite a slight rise.

The analyses above demonstrate that the "talk for writing" approach to some extent changed students' perceptions on themselves, especially the proportion of "passive learners" fell significantly and the figure for "exam-driven learners" and "active learners" saw a considerable rise. Therefore, this approach exerted a positive influence on students' learner identity reconstruction.

However, taking into account of the dynamic and complex context of the classroom, the mathematical numbers and tables may seem to be static and rigid. Even though the figures presented "what" progress students had made and "who" had benefited the most from the approach, they could not depict "how" the progress was made, "how" and "why" the learner identity was reconstructed. Therefore, more qualitative data will be drawn on to complement the limitations of the quantitative data. The findings from the class observations, students' writing samples and interviews are more interesting and they delineate a more vivid and nuanced picture of how students experience writing with a "talk for writing" approach.

\subsection{Class Observations}

The class observations were analyzed according to the types of talk the 4 students engaged in to support their writing, which are as revealed in Jones' Talk into Writing: strategic talk, evaluative talk, and constructive talk [51].

\subsubsection{Strategic Talk}

This type of talk engages students in applying a variety of strategies to generate ideas, shape the structure and address the writing process. Through strategic talk students verbalize their ideas, sound out words phonetically, or even ask peers for certain vocabulary and spelling.

In the first class, the writing task was "summarize the information of the table showing the television viewing figures for sports by country and make comparisons". As this was the first time to employ group talk in writing class, the 4 case-study students were a little bit shy to speak at the beginning and, interestingly, this was more the case with the student Lily who is from the "competent writer" group, perhaps because they were more concerned with making mistakes in speaking. Allen, the boy from the "limited writer" group started the talk by shaping the outline for their group talk. For example, he mentioned the aspects they should cover in analyzing the table, such as "Which sport is viewed the most on TV while which one is watched the least?" "Which country has the most TV viewers for sports and which country has the least?" This contribution seemed to help both Allen and his peers to generate and share ideas and was a typical example of strategic talk. Based on Allen's 
thinking map, Wendy, from the "modest writer" group, extended the talk by suggesting that they should also find out "In the country with the most sports viewers on TV, which sport is the most poplar and which one is the least?"

Judy, the girl from the "limited writer" group, held back and contributed only three sentences to articulate her ideas, other than that, her talk in the first class was mainly asking for prompts from her peers. However, she tried her best to listen to others, prepare what she wanted to say and note down new vocabulary. She felt that asking for prompts, listening and taking notes were her strategies to support her writing and learning. In this sense, asking for prompts from peers was Judy's strategic talk to generate and articulate her ideas for writing.

Most of the talk in the first class progressed smoothly, but sometimes, students would ask their peers to translate certain Chinese expressions into English when they could not retrieve the exact words to express themselves. For example, Judy got stuck at the phrase "the least favorite" and Lily thought hard for the word "maximum". With the prompts from the group, they were able to verbalize their ideas with the English translation. In this sense, students needed help in translating their ideas in Chinese to English. On the other hand, how could this kind of translation not be regarded as a type of strategic talk in EFL classes? This means they were still relying on their first language to think and translate when it was difficult for them to articulate their inner speech due to the failure to retrieve appropriate foreign language vocabulary or grammar [52]. As analyzed by Cohen, thinking in first language lessens the load on working memory (responsible for temporarily holding information available for processing) and releases cognitive processing capacity [53]. Thinking in first language is inevitable as proficiency restricts the thinking in foreign language [52]. From this stance, first language played a supportive role in strategic talk.

\subsubsection{Constructive Talk}

This type of talk emphasizes the social interactions of participants in the co-construction of learning through negotiation, speculation and prompting.

The gathering of ideas on writing topic 7, "The Internet has as many disadvantages as it does advantages.", was a vivid representation of constructive talk.

Everyone in the group talk was aware of the necessity of being critical. First, Lily raised that they totally agree with the statement in the topic and they should analyze this topic from two sides. Then Judy put forward an advantage "Internet can make people has VR travel. Travel around the world without leaving home.". Allen added "The Internet makes our life convenient. We can find any information anytime, anywhere, and contact any friends.". Wendy contributed a disadvantage "People may get addicted to online games". And Lily added "There is a lot of bad information online". During this process, students negotiated their ideas and co-constructed what the advantages and disadvantages of the internet are.
In general, the talk was fruitful in generating ideas for writing even though there were deadlocks where their thinking stuck and they fell back on speaking Chinese. Collaboratively, students depicted the benefits and drawbacks of the internet.

\subsubsection{Evaluative Talk}

This type of talk focuses on students' evaluation of the ideas, sentence patterns, vocabulary choices and other aspects of writing.

During the talk of topic 8, "Which is more important, money and possessions or family and friends?", students evaluated and negotiated the meanings of the English words said by themselves and by others. For example, when Allen described the feeling when the short-term happiness brought by money elapsed, he said three words consecutively, "alone" "lonely" "loneliness". He evaluated his word choice during his own talk, and selected the most suitable one for his discourse.

During the talk of topic 11, "Governments should introduce health care which prevents illness rather than cures it.", Wendy repeated at least 3 times "treating illness..." until she constructed a sentence as "Treating illness is when... after sick, which usually makes people miserable compared to preventing illness." to make the point that the government should inform people how to prevent illnesses rather than make people suffer during medical treatments. She continued "treating illness..." intending to alter her expression and other students also tried to find better expressions and sentence patterns to express the meaning Wendy wanted to convey. Allen structured the sentence as "People feel pain in medical treatment but no pain in illness prevention.". And Judy raised the word "suffer", saying "People suffer a lot during the treatment." Then Lily summarized with a more concise sentence "Treating illness usually makes people suffer.".

This episode is a good example of "evaluative talk" in the sense that the students evaluating other peers' speech, speculating on their own thinking and at the same time prompting others' thinking. The articulation of thinking illustrated how learning evolved from group talk.

\subsection{Students' Writing Samples}

The analyses and discussions of writing samples places the emphasis on three aspects to demonstrate how small-group talk supports students' writing: generating ideas for writing, using talk as oral rehearsal in preparation for writing, improving the linguistic elements in writing, including sentence patterns, grammar, and vocabulary.

\subsubsection{Generating Ideas}

Many early stage writers struggle with what to say about a particular topic, that is with "generating the ideas". The small-group talk provided an ample opportunity for students to explore the writing topic collaboratively to generate ideas for writing through elaboration, speculation, negotiation and prompting.

On topic 3, "Young people should spend more time on 
cultural activities such as music and theater and less time on sport.", students first made their stance clear that they favored spending more time on cultural activities. Then they discussed the benefits of participating in cultural activities and critically they depicted the potential adverse impacts of spending too much time on cultural activities. Further, they analyzed why young people should not spend too much time on cultural activities and critically talked about the benefits of doing exercises. Through talk, they worked collaboratively to generate ideas to enrich the content of their writings. For instance, Allen wrote in his writing to illustrate the benefits of cultural activities "Cultural activities can broaden young people's horizons, and enhance their social skills.". Lily wrote "It can improve their aesthetic taste and edify their sentiment." to demonstrate the support of cultural activities to young people's mental development. To specify the side effects of spending too much time on cultural activities, Wendy wrote down "too much cultural activities will reduce the time of exercise, thus reducing the immunity of young people, easy to get sick". And Judy put down sentences like "Moderate participation in physical exercise can keep the body healthy. And it's conducive to the elimination of mental tension and pressure." to deliberate the benefits of doing sports.

\subsubsection{Using Talk as Oral Rehearsal in Preparation}

Students used their group talk to rehearse what they would write down in their writings. In this process, they verbalized their thinking and the discourse was the representation of the written texts.

Take topic 5 about describing the line graph of the percentage of tourists who visited Edinburgh attractions for example. Starting from Judy, she introduced the writing task and outlined the talk at the beginning of the talk. Then one by one, they analyzed the main features of each line. Everyone contributed their analyses. At last, the teacher prompt them on giving feedback to each other and pointed out they should pay attention to the tense.

Reflecting what Wendy had said "The percentage of tourists to Castle experienced a significant rose (rise) from $24 \%$ to about $45 \%$ between 1918 (1980) and 1995, reach (reaching) its poke (peak) in 1995.", she then wrote down in her writing "The percentage of tourists to Castle experienced a significant rise from $24 \%$ to about $45 \%$ between 1980 and 1995, reaching its peak in 1995.". Lily organized her speech in the talk as "Between 1980 and 2010 the proportion of visitors to zoos lie... (looking at others for prompts, Wendy gave her a hint, and Lily looked up the word in the dictionary on her phone, fluctuated) fluctuated a little from 1980 to 2000. There are some fluctuation in vating, visiting rates, rites (rates) of to, between about $9 \%$ and around $15 \%$. And from 2000 and 2010, the number of people going to zoos, rite (rose) about 20\%.", and she put down the sentence in her writing as "From 1980 to 2010, the proportion of visitors to zoos fluctuated a little. The percentage of visitors to Zoo fluctuated between $9 \%$ and $15 \%$ from 1980 to 2000 . And from 2000 to 2010 , the proportion of people going to Zoo rose to about $20 \%$.".

It is clear from these examples of moving from talk to writing that the group talk before writing contributed much to their writing in terms of ideas, sentence patterns, vocabulary choice, etc., basically, they can write down what they said in talk. Despite the pronunciation mistakes and grammar mistakes, the talk went on smoothly. The fluent talk among the students represented their fluent thinking in writing. And the grammar mistakes were mostly corrected in the writings they conducted.

\subsubsection{Improving the Linguistic Elements}

Learning English as a foreign language, the application of linguistic patterns, the accuracy of grammar, spelling and vocabulary choice are of significance to the written production as they are important indicators in the marking of English writing in exams. The talk for writing approach in EFL writing classes also addressed the linguistic elements but in a different way. Through talk students develop their English thinking. Hence, when they conduct writing, the thinking in English aligns to their writing.

Take the writing samples of the post-test about a discussion on whether economic development is governments' most important goal for example. Compared with the pretest writings, all the students have made great progress. For instance, Lily structured a piece of writing with clear idea organization, key linking words and standard expressions. She used a spectrum of linking words such as "in the same way" and "meanwhile", and standard expressions as "to safeguard the safety of people's lives and property and safeguard national territorial integrity.". Judy used an attributive clause to show the significance of economic development in the governance of a country "the government needs to ensure the stable operation of various affairs, which is impossible without money." Also, she used the sequencing adverbs as "firstly", "secondly" to structure and state the reasons why economic development should be taken as the most important goal. Wendy employed the correlative conjunction as "not only... but also..." and Allen wrote down "on the other hand", "because", "rather than" etc. to achieve better coherence and cohesion.

Even though there were a number of technical errors in the writing samples, the examples above clearly indicated the positive impacts the group talk had on the linguistic elements of students' writing.

\subsection{The Interviews}

Findings and discussions from the interviews with students will be presented in relation to "themes" across the whole case-study group: reflections on the "talk for writing" approach; the impact of talk for writing on their language learner identity.

\subsubsection{Reflections on the Talk for Writing Approach}

Students' reflections on the new approach mainly centered on how the new approach supported their writing.

Lily, Wendy, Judy and Allen all like this approach and 
considered the talk before writing as a key feature of the new approach. Also, they spoke about how this change supported their writing, for example, helping correct the grammar and vocabulary mistakes, building confidence, enhancing engagement, generating and communicating ideas and serving as the oral rehearsal before writing. Below are some of the students' responses and the discussions.

(1) Lily: Yes, I like it. It helped me expand my thoughts in writing topic, at the same time, I make, made, less grammar mistakes to make sure the correctness of sentences. And I am much more confident in English writing.

Lily clearly depicted how talk helped her in expanding thinking, improving grammatical correctness, and building up her confidence in writing.

(2) Wendy: Er, I like this approach because my classmates can help me. My classmates can... er, can help me, 纠正 ("correct" in Chinese), help,

Me: Correct?

Wendy: Oh, 对("right" in Chinese), correct my, my 错误 ("mistakes" in Chinese), mistakes.

Wendy: During the discussing approach, it can not only share our different ideas but also think about the questions in detail with more ideas. Er, in the time, in the meantime, we, I can... I can, 怎么("how" in Chinese), er, increase my encouragement to learn English.

Me: So, your confidence?

Wendy: Oh, confidence.

In this dialogue, Wendy used some Chinese words to help her think. She got stuck at expressing "correct my mistakes" but her meaning is clear and she focused on an aspect of writing that is in many ways more important than notions of "correctness": the opportunity to express one's ideas and to share this with others in talk.

(3) Allen: Er, during this time we have more English speaking time than before. And I think, and I think, it is helpful. I like talking with my classmates than working by myself. Talk with... with them, I feel energetic, I feel, feel, feel, motivation in the class.

......

Allen: Yes. I can write what I said.

Allen liked working with peers and felt that speaking helped his writing in the way of writing down what he said in the discussion. This view demonstrated how talk supports writing through oral rehearsal and how talk enhanced his engagement, in other words, agency and investment, in class.

(4) Judy: It is a good way. I like it. I like communicating with others. It helps me think more ideas. For example, to an, an, unfamiliar topic, sometimes my thinking is limited, but through talking with my classmates, I get illuminated by their ideas and I can think of more ideas. Also, From this I can learn more about vocabulary and improve my grammar in writing and spelling and so on.

Judy also explicitly expressed she liked the approach. She liked communicating because it helped her to generate more ideas. Besides grammar, she referred to her improvement in vocabulary and spelling.

The aspects students mentioned such as the development of the students' confidence, the enhancement of agency and investment, their ability to generate and develop ideas in dialogue with each other, their sense of thinking and talking in English are more significant areas that "talk for writing" addresses and supports even if the linguistic aspects "carry a great deal of weight" for standard exams and so are seen by students and teachers as most important.

\subsubsection{The Impacts on Students' Language Learner Identity}

Lily and Wendy, the two girls from the "competent writer" group and "modest writer" group respectively, explicitly expressed that this approach has aroused their interest and motivation in writing and boosted their confidence. At the end of the implementing semester, they were confidently regarded themselves as "English writers". Even though Judy, the girl from the "limited writer" group, witnessed her progress in writing, she still thought herself as an "English speaker" not "writer". Allen, the boy from the "limited writer" group, praised the approach a lot in the way helping him generate ideas, extend thinking, enlarge vocabulary, on the other hand, regarded himself as not a good language learner, claiming that he was not confident in any of the four English language skills, listening, speaking, reading and writing. Some of the students' responses and the discussions are presented below.

(1) Lily: The talk for writing approach is helpful in improving my interest, motivation and confidence. I am not afraid of writing now. When I see a writing topic, I know how to structure and what to write. In high school, we just recited the model texts and change words in exams. I think I am an "English writer" now because I can write what I think, not to write with the model texts.

Seeing from Lily's description, this approach not only enhanced her confidence in writing but also endowed her the power to write what she wanted to say, breaking the shackle of reproducing model texts.

(2) Wendy: Yes, I can see me as an "English writer", because in high school, I can't write what I think, and I have to recite the model... writings but now I can write what I think, because I know what to write and how to put the thinking in different paragraphs.

Wendy's reply demonstrated her identity change from a non-"English writer" to "English writer". In contrast with the reciting model text in high school, she could produce her own writing with her own ideas and organization.

(3) Judy: This approach did improved my confidence in writing but no, no, I don't think I am an "English writer" because I am not as confident as speaking. When I speak, I can say what I think fluently, but when I am writing, I have to think about many other things, like grammar, sentence patterns and spelling. The reason why I am not good at writing is I have a bad memory and I am lazy. I keep forgetting the words I've memorized a day before and I am lazy to practice writing.

Indeed, Judy's pronunciation and oral communication is among top three in her grade among 74 students. However, she did not regard herself as an "English writer". The reason 
may lie in the gap of her command of English speaking and writing. Compared with speaking, she was not confident enough to call herself "English writer". She took writing as harder work than speaking.

(4) Allen: I am not a good English learner. My... my base is very poor. The new approach helped me think more... more ideas, let me know what to write first, what to write second, and help me learn many new words. It im...im ... improved my motivation and confidence a little but not a lot. I am not confident in writing by myself.

As Allen analyzed above, his perception of himself as a limited language learner hindered his confidence in learning. For one thing, he recognized the efficacy of "talk for writing" to his writing, for another, he was afraid of regarding himself as an "English writer".

As for the impact of "talk for writing" to students' language learner identity, they all recognized the positive role of talk in promoting their interest, engagement, motivation and confidence in writing. And two students, Lily and Wendy, from the "competent writer" group and the "modest writer" group, were confident enough to regard themselves as "English writers" who could paint the pictures in their minds with words. The girl, Judy, and the boy, Allen, from the "limited writer" group both were diffident to call themselves "English writers". Nevertheless, they depicted distinct language learner identity trajectories. Judy, who has a good command of English listening and speaking, believed her speaking was much better than her writing. The gap was so large that her confidence in writing lay at the bottom before the intervention. Even though her level of confidence was pulled up by the "talk for writing" approach, it still comparatively considerable lower than that in speaking. In regard to Allen, despite the increase of confidence in writing, he was diffident in English learning, regarding himself as a "limited English learner" which also hampered his "English writer" identity recognition.

To sum up, based on the findings and discussions of the quantitative data and qualitative data, the three research questions can be addressed.

(1) What does talk entail?

Talk is a process during which thoughts are deliberated, ideas are exchanged, knowledge is co-constructed, development is achieved, and identity is negotiated.

(2) In what ways does classroom talk affect college students' academic English writing?

Quantitatively speaking, it significantly improved students' academic attainment in English writing on the whole, according to the results of the paired samples t test on the gap of the mean scores of the pretest and the post-test of the 74 participants. Also, students from the "modest writer" group made the greatest progress with the largest increase of 11.09 marks in mean scores.

Qualitatively speaking, it helped students with generating ideas for the content, using talk as oral rehearsal in preparation for writing and improving the linguistic elements in writing such as sentence patterns, grammar and vocabulary. Moreover, in the affective aspect, it enhanced students' engagement, motivation and confidence in English writing. In general, all the case study students made progress in their writing although the trajectories of development were not exactly the same. To high attaining student, Lily improved her ability in generating ideas, enhanced her accuracy in grammar and her confidence in writing. As for the average attaining student, Wendy made great progress in generating ideas and ensuring the correctness of grammar, also this approach boosted her confidence. As to the students from the low attainment group, Allen enhanced his ability to use talk as oral rehearsal in preparation for his writing and boosted his motivation and engagement in class. Judy improved her ability for communicating and generating ideas, particularly, improved her accuracy in grammar, vocabulary and spelling.

(3) How has talk affected their language learner identities?

From the quantitative perspective, the analyses of the questionnaires answered before and after the implementation of "talk for writing" approach show that this approach played a positive role in the dynamic change of students' language learner identity. The percentage of "passive learners" witnessed a dramatic fall while the figure for "exam-driven learners" and "active learners" grew considerably.

From the qualitative perspective, different students delineated distinct language learner identity changing trajectories. All the four case-study students recognized the positive impact on the boosting their "agency" and "investment" in learning writing, among whom two students, Lily and Wendy, from the "competent writer" group and the "modest writer" group confidently viewed themselves as "English writers", in contrast, the other two, Judy and Allen from the "limited writer" group were diffident to regard themselves as "English writers" out of different concerns. The two who viewed themselves as "English writers" recognized the change in the way writing was taught in college and built up their confidence in writing during the talk for writing implementing process, accepted their "English writer" identity confidently. However, the reason why Judy did not consider herself as an "English writer" lay in that the gap between her capacity in speaking and writing was so big that her confidence in English writing was weakened significantly, while, Allen's lack of confidence in learning English language across the board impeded his identity negotiation and change.

\section{Conclusions}

The findings of the research demonstrated the possibilities of "talk for writing" approach in Chinese college classrooms and its success.

Based on the quantitative analyses, it enhanced the confidence, interest and motivation in writing of the majority of students and significantly improved students' academic attainment in English writing. Particularly, students from the "modest writer" group benefited the most as they made the greatest progress in writing in terms of the increase of mean scores.

Further, the qualitative analyses of class observations, 
writing samples and interviews demonstrated more complex and dynamic findings. They provided evidence for the ways in which talk supported students' ability to generate ideas, to use talk as oral rehearsal in preparation for writing, and to improve their accuracy in linguistic elements such as sentence patterns, grammar and vocabulary. Moreover, they demonstrated individual students' views on the talk for writing approach and delineated their language learner identity changing trajectories. This approach, on the whole, enhanced students' motivation, engagement and confidence in English writing. Correspondingly, students' language learner identity experienced dynamic changes from passive learners to exam-driven learners and active learners.

\section{Follow-up Studies}

First, follow-up studies can prolong the research span to a whole academic year or longer to see the effects.

Second, communicative writing such as letters of invitation, letters of thanks, letters of apologies, etc. can be set as the focus in the future work.

Third, the subjects of the follow-up studies can be extended to students of diverse majors such as digital media, arts, business administration, etc.

\section{Acknowledgements}

This work was supported by the China Foreign Language Education Foundation under Grant ZGWYJYJJ10A026.

\section{References}

[1] Hu, G. (2002). Potential cultural resistance to pedagogical imports: The case of communicative language teaching in China. Language, Culture, and Curriculum, 15 (2), 93-105.

[2] Hu, G. (2005). Contextual influences on instructional practices: A Chinese case for an ecological approach to English language teaching. TESOL Quarterly, 39, 635-660.

[3] Spaulding, E., Wang, J., Lin, E., \& Hu, G. (2009). Analyzing voice in the writing of Chinese teachers. Research in the Teaching of English, 44 (1), 23-50.

[4] British Council of Culture and Education. (2018). The white paper on academic performance and English learning behavior of IELTS candidates from China mainland. Available at: https://www.chinaielts.org/white_paper_2017.html [Accessed on 10th September, 2021].

[5] You, X. (2004a). The choice made from no choice: English writing instruction in a Chinese university. Journal of Second Language Writing, 13 (2), 97-110.

[6] Yunus, M. M., N. Nordin, H. Salehi, C. H. Sun, and M. A. Embi. (2013). Pros and Cons of Using ICT in Teaching ESL Reading and Writing. International Education Studies, 6 (7), 119-130.

[7] Atkinson, D., T. Nishino, E. Churchill, and H. Okada.(2007). Alignment and interaction in a sociocognitive approach to second language acquisition. The Modern Language Journal $91(2), 169-88$.
[8] Wang, C., \& Wang, M. (2014). Effect of alignment on L2 written production. Applied Linguistics, 36, 503-526.

[9] Huang, Y. \& Fan, H. (2014). Review and prospect of English writing teaching research in higher vocational colleges in China. Journal of Heilongjiang Institute of Education, 12, 186-187.

[10] Ji, J. (2020). "Reading to promote writing" in higher vocational college English writing teaching. Journal of Cultural and Educational Materials, 6, 231-233.

[11] Xie, F. (2019). Application research of "combination of reading and writing, reading to promote writing" mode in higher vocational English writing teaching. Journal of Hunan Posts and Telecommunications Vocational Technical College, 6, 101-103.

[12] Wu, X. (2019). The impact of writing continuation after reading on the teaching of English writing in higher vocational colleges. Overseas English, 24, 255-256.

[13] Corbett, P., \& Strong, J. (2011). Talk for writing across the curriculum: How to teach non-fiction writing to 5-12-year-olds. Maidenhead: Open University Press.

[14] Parr, J., Jesson, R. \& McNaughton, S. (2009). Agency and platform: the Relationships between Talk and Writing. In R. Beard, D. Myhill, J. Riley \& M. Nystrand (Eds.), SAGE Handbook of writing development (pp. 246-259). London: SAGE.

[15] Fisher, R., Jones, S., Larkin, S., \& Myhill, D. (Eds.). (2010). Using talk to support writing. London: SAGE.

[16] Shu, Y. (2019). Improving the effectiveness of English writing teaching in junior middle school by using speaking to promote writing and the combination of speaking and writing. Cultural and Educational Materials, 12, 233-234.

[17] Wei, J. (2019). A study on the "talk for writing" approach in the teaching of English writing in middle school. Journal of Learning Weekly, 11, 112.

[18] Yang, B. (2011). High school English Class design of reading, talk and writing activities. Journal of Basic English Education, $13(6), 59-62$.

[19] Yang, L. (2018). A study on "talk for writing" teaching practice in junior middle school English writing based on guided learning cooperation. English Teachers, 1, 139-143.

[20] Zhang, M. (2015). Research on the combination of speaking and writing in the process approach in English writing teaching. MA Thesis of Central China Normal University. Available at: http://www. cnki.net [Last accessed on 20th June, 2020].

[21] Wang, H. Q. (2016). Apply the pedagogy of talk and writing combination to cultivate vocational college students' English writing capability. Journal of Hubei University of Science and Technology, 36 (2), 107-110.

[22] Vygotsky, L. S. (1978). Mind in society. Cambridge: Harvard University Press.

[23] Britton, J. (1970). Language and learning. Harmondsworth: Penguin.

[24] Barnes, D., Britton, J., \& Rosen, H. (1969). Language, the learner and the school. Harmondsworth: Penguin. 
[25] Vygotsky, L. S. (1986). Thought and language. Cambridge, MA: MIT Press.

[26] Mercer, N., Dawes, L., Wegerif, R., \& Sams, C. (2004). Reasoning as a scientist: Ways of helping children to use language to learn science. British Educational Research Journal, 30 (3), 359-377.

[27] Reznitskaya, A., Kuo, L.-J., Clark, A.-M., Miller, B., Jadallah, M., Anderson, R. C., \& Nguyen-Jahiel, K. (2009). Collaborative reasoning: a dialogic approach to group discussion. Cambridge Journal of Education, 39 (1), 29-48.

[28] Sutherland, J. (2015). Going 'meta': using a metadiscoursal approach to develop secondary students' dialogic talk in small groups. Research Papers in Education, 30 (1), 44-69.

[29] Boaler, J. (2008). Promoting 'relational equity' and high mathematics achievement through an innovative mixed-ability approach. British Educational Research Journal, 34 (2), 167-194.

[30] Mercer, N., \& Sams, C. (2006). Teaching children how to use language to solve maths problems. Language and Education, 20 (6), 507-528.

[31] Palinscar, A. S., \& Brown, A. L. (1984). Reciprocal teaching of comprehension-fostering and comprehension-monitoring activities. Cognition and Instruction, 1 (2), 117-175.

[32] Alexander, R. J. (2008). Towards dialogic teaching: Rethinking classroom talk. 4th ed. Cambridge: Dialogos.

[33] Beard, R. (2015). Talk for Writing: Review of related research Available http://www.primarywritingproject.org.uk/review-of-supportin g-evidence/ [Accessed on 22nd August, 2021].

[34] Christie, F. (1987). Young children's writing: from spoken to written genre. Language and Education, 1 (1), 3-13.

[35] He, J. (2012). On the construction of online teaching mode of "speaking to promote writing". Journal of Inner Mongolia Agricultural University (Social Science Edition), 2, 115-117.

[36] Alexander, R. J. (2008b). Culture, dialogue and learning: Notes on an emerging pedagogy. In N. Mercer \& S. Hodgkinson (Eds.), Exploring talk in school (pp. 91-114). Los Angeles: Sage.

[37] Alexander, R. J. (2018). Developing dialogic teaching: genesis, process, trial. Research Papers in Education, DOI: $10.1080 / 02671522.2018 .1481140$.

[38] Norton, B. (2000). Identity and language learning: Gender, ethnicity and educational change. London: Longman.

[39] Norton, B. (2013). Identity and Language Learning:
Extending the Conversation (2nd Ed.). Bristol, UK: Multilingual Matters.

[40] Hawkins, M. R. (2005). Becoming a student: Identity work and academic literacies in early schooling. TESOL Quarterly, $39(1), 59-82$

[41] Ellis, R. (1994). The study of second language acquisition. Oxford: Oxford University Press.

[42] Timmis, I. (2007). The attitudes of language learners towards target varieties of the language. In B. Tomlinson (Ed.), Language acquisition and development: Studies of learners of first and other languages, (pp. 122-138). London and New York: Continuum.

[43] Norton Peirce, B. (1995). Social identity, investment, and language learning. TESOL Quarterly, 29 (1), 9-31.

[44] Norton Peirce, B. (2016). Identity and language learning: Back to the future. TESOL Quarterly, 50 (2), 475-479.

[45] Block, D. (2007). Second Language Identities. London: Continuum.

[46] Norton, B. \& Toohey. K. (2011). Identity, language learning and Social Change, Language Teaching, 44 (4). 412-446.

[47] Darvin, R. \& Norton, B. (2015). Identity and a Model of Investment in Applied Linguistics. Annual Review of Applied Linguistics. 35, 36-56.

[48] Brown, A. L., \& Campione, J. C. (1990). Communities of learning or a context by any other name. In D. Kuhn (Ed.), Contributions to human development (Vol. 21, pp. 108-126). Basel, NY: Karger.

[49] Brown, A. L., \& Campione, J. C. (1994). Guided discovery in a community of learners. In K. McGilly (Ed.), Classroom lessons: Integrating theory and classroom practice (pp. 229270). Cambridge, MA: MIT Press/Bradford Books.

[50] Reams, P., \& Twale, D. (2008). The promise of mixed methods: discovering conflicting realities in the data. International Journal of Research and Method in Education, 31 (2), 133-142.

[51] Jones, S. (2010). Talk into writing. In R. Fisher, S. Jones, S. Larkin \& D. Myhill (Eds.), Using talk to support writing (pp. 82-107). London: SAGE.

[52] Cohen, A. D., \& Brooks-Carson, A. (2001). Research on direct versus translated writing: Students' strategies and their results. The Modern Language Journal, 85, 169-188.

[53] Cohen, A. D. (2000). Strategies in learning and using a second language. Beijing: Fltrp. 